\title{
Environmental Public Health Week
}

\section{Ann Thomas}

National President CIPHI

The annual Environmental Public Health Week was held 26-30 September 2016. This celebration is sponsored by the Canadian Institute of Public Health Inspectors (CIPHI) to recognize, promote, and celebrate the important contributions of Environmental Public Health Professionals across Canada.

This year's theme was "Innovation Beyond Inspection". The 21st Century has seen a shift in the typical role of Environmental Public Health. As Environmental Public Health Professionals, we continue to be involved in the inspection, enforcement, and education of a wide range of programs and services. We must also adapt to new environmental public health challenges. Modern-day challenges now include the pressures of water scarcity, food security, and the re-emergence of vaccine-preventable diseases. Constant change in industries, such as novel personal services, and innovations in food technology require us to have dynamic understanding of human health risk and public health promotion.

Within the spectrum of Canadian healthcare, Environmental Public Health Professionals are an integral and important component. The opportunity for health begins where we live, work, and play. Public health advances such as safer and healthier foods, control of infectious diseases, healthier environments, and the recognition of tobacco use as a health hazard have contributed significantly to Canadians living longer. Our commitment and leadership in activities addressing the broad determinants of health has never been stronger.

Our profession continued to flourish in 2015 with over 100 new certificates in public health inspection awarded nationally, and a new school (the 7 th) receiving approval for its Environmental Health Program from the CIPHI Board of Certification. We should all take pride in the unique and invaluable work we do to serve and protect the health of all Canadians.

In the future, I encourage all Certified Public Health Inspectors to use Environmental Public Health Week to promote the great work they do and to forge new partnerships within your communities and abroad.

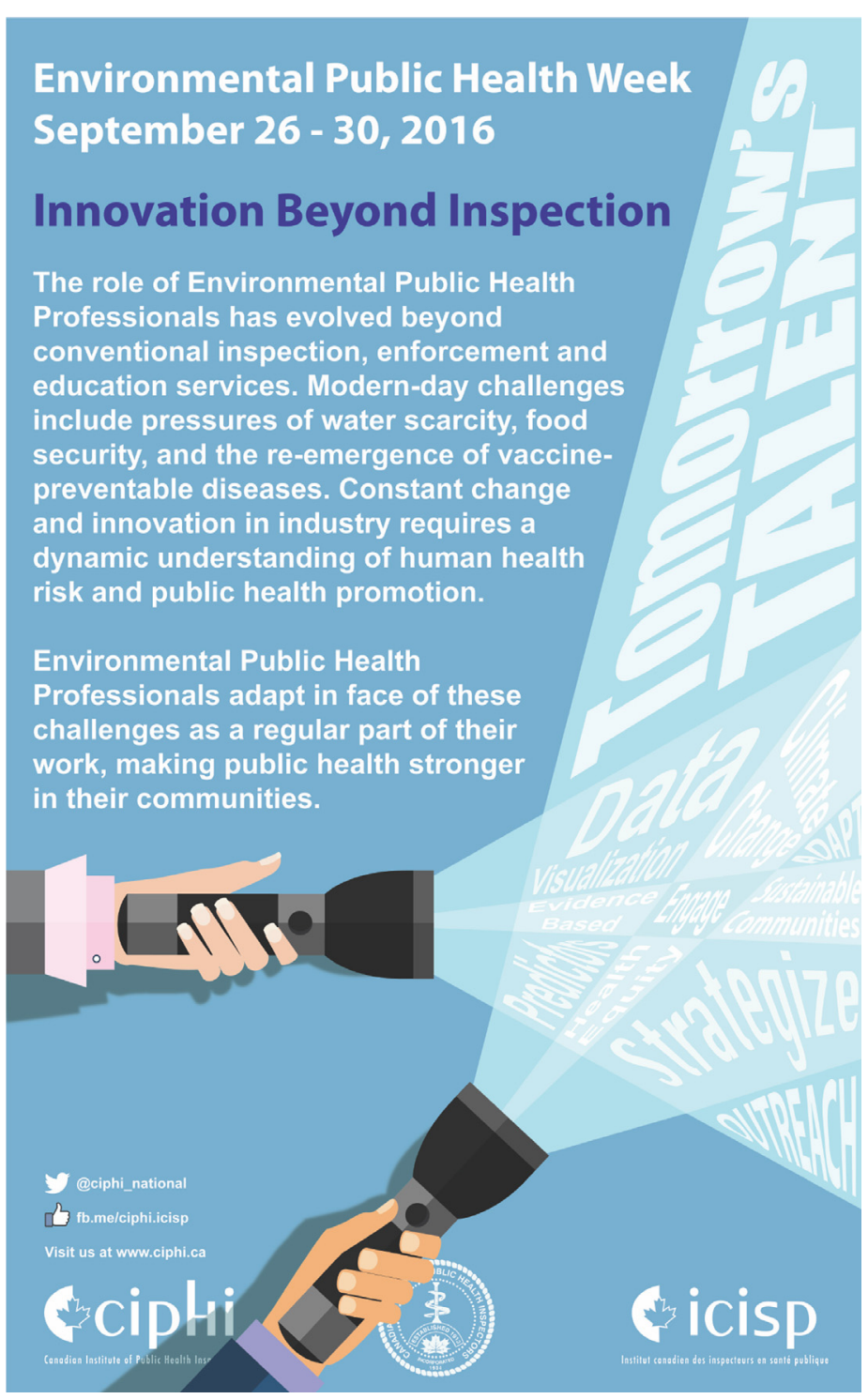

